(C) The Authors 2014

\title{
Effect of oat intake on glycaemic control and insulin sensitivity: a meta-analysis of randomised controlled trials
}

\author{
Lei Bao, Xiaxia Cai, Meihong Xu and Yong Li* \\ Department of Nutrition and Food Hygiene, School of Public Health, Peking University, No. 38, Xueyuan Road, \\ Haidian District, Beijing 100191, People's Republic of China
}

(Submitted 6 January 2014 - Final revision received 14 March 2014 - Accepted 24 March 2014 - First published online 30 April 2014)

\begin{abstract}
The present meta-analysis of randomised controlled trials (RCT) aimed to investigate the effect of oat intake on glycaemic control and insulin sensitivity. A literature search was carried out in PubMed, ScienceDirect Online and The Cochrane Library (up to October 2013) for RCT that assessed the effect of oat intake on glucose control and insulin sensitivity. A total of fifteen articles with 673 subjects met the inclusion criteria. A random-effects model was used when the overall pooled studies exhibited significant heterogeneity. Otherwise, a fixed-effects model was used. Compared with controls, oat intake significantly reduced the concentrations of fasting insulin by $-6 \cdot 29$ $(95 \% \mathrm{CI}-12 \cdot 32,-0 \cdot 27) \mathrm{pmol} / \mathrm{l}(P=0 \cdot 04)$ and the values of glucose AUC (GAUC; $0-120 \mathrm{~min})$ by $-30 \cdot 23(95 \% \mathrm{CI}-43 \cdot 65,-16 \cdot 81) \mathrm{min} \times$ $\mathrm{mmol} / \mathrm{l}(P<0 \cdot 0001)$. There was a slight decrease in fasting glucose concentrations, glycated Hb concentrations and homeostatic model assessment-insulin resistance values in subjects who consumed oats, but the difference was not significant. In conclusion, oat intake significantly lowers fasting insulin concentrations and GAUC values. To further investigate the effect of oat intake on fasting glucose concentrations, additional long-term and high-quality RCT with a parallel design are required.
\end{abstract}

Key words: Oats: $\beta$-Glucan: Glycaemic control: Meta-analyses: Type 2 diabetes mellitus

Diabetes mellitus (DM) is one of the most serious chronic diseases the incidence rate of which is increasing sharply globally. The number of people with DM has more than doubled globally over the past three decades ${ }^{(1)}$. There had been an estimated 285 million diabetics in 2010, $90 \%$ of whom had type 2 diabetes mellitus (T2DM). Moreover, this number is projected to increase to 439 million by 2030, representing $7.7 \%$ of the total adult population of the world aged 20-79 years $^{(2)}$. DM (especially type 2 ) used to be the most common disease in developed countries. However, the greatest increase in prevalence is expected to occur in Asia and Africa. Perhaps, a 'Western-style' diet is the most important factor for the increase in the incidence of DM in developing countries $^{(3)}$. In addition, there is no obvious cure for DM, except in very specific situations. The main management mechanism is keeping blood glucose concentrations as close to normal as possible, without causing hypoglycaemia. It has been demonstrated that the complications of diabetes are far less common and less severe in people who have wellmanaged blood sugar concentrations ${ }^{(4)}$. Glycaemic control can usually be accomplished with diet, exercise and use of appropriate medications ${ }^{(5)}$. A number of efficacy trials have provided strong evidence for the prevention of T2DM among individuals with impaired glucose tolerance through lifestyle change programmes ${ }^{(6,7)}$. Therefore, exploring healthy diet and lifestyle to control blood glucose concentrations is critical for the prevention of T2DM.

Oats, which are considered to be unique among the cereals, belong to the Poaceae family and are known as 'Jai' or 'Javi' in the Indian subcontinent ${ }^{(8)}$. In the mid-1980s, oats were recognised as a healthy food helping prevent heart disease and then became more popular in human nutrition ${ }^{(9)}$. The common oat (Avena sativa) is the most important crop among the cultivated oats. Oats are suitable for human consumption as oatmeal, rolled oats and other oat-enriched products. Recent studies in food and nutrition have revealed the importance of the various components of oats, such as dietary fibre, especially $\beta$-glucan, minerals and other nutrients ${ }^{(8)}$. Oats and oat-enriched products have been proven to control blood glucose concentrations and to be helpful in the treatment of diabetes. However, the results of clinical trials in human subjects that have investigated the effect of oat intake on glycaemic control and insulin sensitivity are inconsistent. Several studies have suggested that oats and oat-enriched diets can

Abbreviations: DM, diabetes mellitus; GAUC, glucose AUC; HbA1c, glycated Hb; HOMA-IR, homeostatic model assessment-insulin resistance; RCT, randomised controlled trials; T2DM, type 2 diabetes mellitus.

*Corresponding author: Professor Y. Li, fax +86 10 82801177, email liyongbmu@163.com 
significantly decrease insulin responses and fasting and postprandial hyperglycaemia in overweight and type 2 diabetic subjects ${ }^{(10-15)}$, which is mainly attributed to the markedly functional properties and enormous importance of $\beta$-glucan in human nutrition. $\beta$-Glucan is a kind of high-molecular weight polysaccharide exhibiting high viscosity at relatively low concentrations, which can reduce mixing of the food with digestive enzymes and delay gastric emptying. Increased viscosity also retards the absorption of glucose $^{(16,17)}$. However, some studies have found that there are no dietrelated effects on glycaemic control or insulinaemic responses to oat-enriched products ${ }^{(18-21)}$. Therefore, we conducted a meta-analysis of randomised controlled trials (RCT) to quantitatively assess whether oat intake has a beneficial effect on glycaemic control and insulin sensitivity and to make some suggestions regarding diabetes diet based on what we find.

\section{Methods \\ Search strategy}

A search for all the published RCT on the effect of oat intake on glycaemic control and insulin sensitivity was carried out independently by two authors (L. B. and X. C.). This systematic search was conducted in three databases PubMed, ScienceDirect Online and The Cochrane Library up to October 2013. The search strategy was implemented using the following key words: ('oats' OR 'Avena sativa' OR 'oatmeal' OR 'oat bran' OR 'oat power') AND ('blood glucose' OR 'HbAlc' OR 'glycated hemoglobin' OR 'fasting plasma glucose' OR 'glycolated hemoglobin' OR 'FBG' OR 'insulin'). The search was restricted to studies in human subjects that were published in English.

\section{Inclusion and exclusion criteria}

The inclusion criteria of the meta-analysis were as follows: RCT conducted in human subjects with a parallel or crossover design; use of any type of oat-enriched product as the intervention product in the studies; use of data with available means and standard deviations, standard errors or $95 \% \mathrm{CI}$ as the endpoint values for glucose or insulin responses; inclusion of a control group; assessment of differences between the control and treatment groups in the studies based on the effect of oat-enriched product intake. Non-randomised studies and studies that were carried out in vitro were excluded.

\section{Methodological assessment}

Methodological assessment was conducted using the modified Jadad scale ${ }^{(22)}$. It is an eight-item scale designed to assess randomisation, blinding, withdrawals and dropouts, inclusion and exclusion criteria, adverse effects and statistical analysis results (Table 1 ). The score for each article could range from 0 (lowest quality) to 8 (highest quality). The scores of 4 to 8 denote good to excellent quality and 0 to 3 poor to low quality. Critical appraisal was done by one investigator (L. B.) and was verified by another (M. X.).
Table 1. Modified Jadad scale with eight items

\begin{tabular}{llr}
\hline Items assessed & Response & Score \\
\hline Was the study described as & Yes & +1 \\
randomised? & No & 0 \\
Was the method of & Yes & +1 \\
randomisation & No & -1 \\
appropriate? & Not described & 0 \\
Was the study described as & Yes & +1 \\
blinded? & No & 0 \\
Was the method of blinding & Yes \\
appropriate? & No & +1 \\
& Not described & -1 \\
Was there a description & Yes & 0 \\
of withdrawals and & No & +1 \\
dropouts? & & 0 \\
Was there a clear description & Yes & +1 \\
of the inclusion/exclusion & No & 0 \\
criteria? & & \\
Was the method used to & Yes & +1 \\
assess adverse effects & No & 0 \\
described? & & \\
Was the method of statistical & Yes & \\
analysis described? & No & \\
\hline
\end{tabular}

\section{Study identification}

The titles of all the articles that were retrieved were screened independently by two investigators (L. B. and X. C.). The abstract of any study that was potentially relevant to the meta-analysis was reviewed; full text was referred to when the information available from the abstract was inadequate. Discrepancies were resolved by consensus after discussion with a third investigator (Y. L.).

\section{Data extraction}

Detailed information from each article included in the metaanalysis was extracted independently by two investigators (X. C. and M. X.). Disagreements were resolved through discussion with a third investigator (Y. L.). Effective data from all trials including data available for the meta-analysis were collected. Details regarding the first author, publication year, study region, sample size, study design, type of intervention, dose and study duration and information on participants including age, sex, BMI and healthy status were extracted. Primary outcomes consisted of net changes in fasting glucose and insulin concentrations. Secondary outcomes included mean changes in HbA1c concentrations, homeostatic model assessment-insulin resistance (HOMA-IR) values and glucose AUC (GAUC; 0-120 min) values. All values were converted to $\mathrm{mmol} / \mathrm{l}$ for glucose concentrations, $\mathrm{pmol} / \mathrm{l}$ for insulin concentrations and $\min \times \mathrm{mmol} / \mathrm{l}$ for GAUC values.

\section{Statistical analysis}

Net changes in glucose and insulin concentrations were calculated as the weighted mean differences and 95\% CI. Cochran's Q tests were used to assess statistical heterogeneity among the studies $(P<0 \cdot 1)^{(23)}$. The $I^{2}$ statistic was also calculated and $I^{2}>50 \%$ was considered to indicate significant heterogeneity across the studies ${ }^{(24)}$. If the overall pooled studies exhibited 
significant heterogeneity, a random-effects model was used. Otherwise, a fixed-effects model was used. Publication bias was examined using funnel plots and Egger's regression test $^{(25)}$ (significant at $P<0 \cdot 1$ ). Sensitivity analyses were carried out using subgroup analyses, which were used to examine the possible source of heterogeneity in these studies, including regions, healthy status, study design, $\beta$-glucan content in oats, intervention period and Jadad score. In addition, sensitivity analyses were also carried out using the Handbook for Systematic Review of Interventions of Cochrane software (version 5.0.2, The Cochrane Collaboration). Furthermore, dose-effect relationship was investigated using meta-regression analyses. The meta-analysis was carried out using Stata (version 12, StataCorp LP). $P<0.05$ was considered statistically significant.

\section{Results}

\section{Literature search}

In Fig. 1, a flow diagram of the strategy implemented for the selection of studies in the present meta-analysis is shown. A total of 569 articles were initially identified after the removal of duplicates, and after a careful review of the titles and abstracts, 524 articles were excluded as they were not relevant to the present meta-analysis. After full-text examination, fifteen articles that were eligible for inclusion in the metaanalysis were finally identified ${ }^{(12,15,17,19-21,26-34)}$.

\section{Study characteristics}

The characteristics of the fifteen RCT included in the present meta-analysis are summarised in Table 2. The total number of participants in all the studies was 673. Among the articles identified, twelve were selected for reporting the effect of oat intake on fasting glucose concentrations, nine on fasting insulin concentrations, five on GAUC values, three on HbA1c concentrations, and three on HOMA-IR values. The $\beta$-glucan content in oats in the trials ranged from 3 to $10 \mathrm{mg} / \mathrm{d}$ (median $5 \mathrm{mg} / \mathrm{d}$ ). The intervention period in studies reporting the effect of oat intake on glucose concentrations varied from 1 week to 16 weeks (median 8 weeks). Of the fifteen studies, five enrolled healthy individuals, while the remaining ten enrolled individuals with metabolic diseases (patients with T2DM in four trials, overweight individuals in three trials, individuals with high cholesterol concentrations in two trials and individuals with elevated blood pressure in one trial). A parallel design was used in ten studies and a cross-over design in five studies.

Quality assessment was conducted according to the modified Jadad scale ${ }^{(22)}$. Of the fifteen studies, eight $^{(15,17,20,21,27,29,31-32)}$ were classified as high-quality studies (Jadad score $\geq 4$ ) and the remaining seven as low-quality studies (Jadad score $<4$ ).

\section{Effect of oat intake on fasting glucose concentrations}

Data on the effect of oat intake on fasting glucose concentrations were reported by thirteen studies in twelve articles. Overall, no significant difference was observed in subjects who consumed oat-enriched products ( $-0.04 \quad(95 \% \mathrm{CI}$ $-0.17,0.09) \mathrm{mmol} / \mathrm{l} ; P=0.59$; Table 3 and Fig. 2). High heterogeneity was observed among the studies $\left(I^{2}=68 \%\right)$. No significant publication bias was indicated by the funnel plot (Fig. 3) and Egger's test $(P=0 \cdot 49)$. No dose-effect relationship

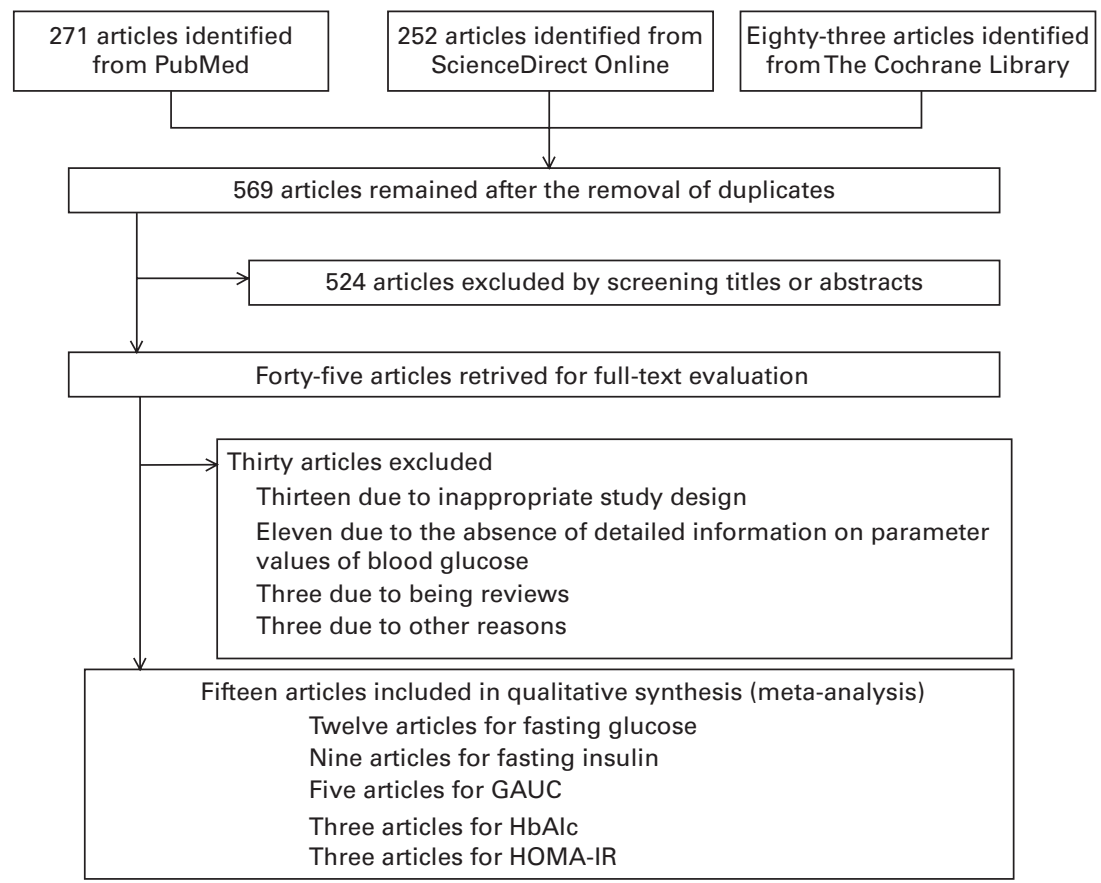

Fig. 1. Flow diagram for the selection of studies on the effect of oat intake on glycaemic control and insulin sensitivity in the present meta-analysis. GAUC, glucose AUC; HbA1c, glycated Hb; HOMA-IR, homeostatic model assessment-insulin resistance. 
Table 2. Characteristics of the fifteen randomised controlled trials included in the present meta-analysis (Number of subjects, mean values and standard deviations)

\begin{tabular}{|c|c|c|c|c|c|c|c|c|c|c|c|c|c|}
\hline \multirow{2}{*}{$\begin{array}{l}\text { Author, publication year, } \\
\text { location }\end{array}$} & \multirow{2}{*}{$\begin{array}{l}\text { No. of } \\
\text { subjects }\end{array}$} & \multicolumn{2}{|c|}{ Age (years) } & \multirow[b]{2}{*}{ Sex } & \multicolumn{2}{|c|}{$\mathrm{BMI}\left(\mathrm{kg} / \mathrm{m}^{2}\right)$} & \multirow[b]{2}{*}{ Subjects } & \multirow{2}{*}{$\begin{array}{l}\text { Study } \\
\text { design }\end{array}$} & \multirow[b]{2}{*}{ Treatment group } & \multirow[b]{2}{*}{ Control group } & \multirow{2}{*}{$\begin{array}{l}\text { Washout } \\
\text { duration }\end{array}$} & \multirow{2}{*}{$\begin{array}{l}\text { Intervention } \\
\text { period }\end{array}$} & \multirow{2}{*}{$\begin{array}{l}\text { Jadad } \\
\text { score }\end{array}$} \\
\hline & & Mean & SD & & Mean & SD & & & & & & & \\
\hline Saltzman, 2001, USA ${ }^{(26)}$ & 43 & 44.6 & $22 \cdot 0$ & $\mathrm{M} / \mathrm{F}$ & $26 \cdot 4$ & 3.3 & Healthy & Parallel & $\begin{array}{r}\text { Diet containing oats } \\
\text { (4.5 g/d } \beta \text {-glucan })\end{array}$ & Usual food & NR & 8 weeks & $<4$ \\
\hline Davy, 2002, USA ${ }^{(27)}$ & 36 & $57 \cdot 0$ & $2 \cdot 0$ & M & $29 \cdot 6$ & 0.8 & Overweight & Parallel & $\begin{array}{c}\text { Oatmeal and oat bran } \\
\text { (5.5 g/d } \beta \text {-glucan })\end{array}$ & Wheat cereal & NR & 12 weeks & $<4$ \\
\hline Tapola, 2004, Finland ${ }^{(12)}$ & 12 & 66.0 & 7.0 & $\mathrm{M} / \mathrm{F}$ & $28 \cdot 9$ & 3.5 & Type 2 diabetes & Cross-over & $\begin{array}{l}\text { Oat bran crisp } \\
(3.0 \mathrm{~g} / \mathrm{d} \beta \text {-glucan })\end{array}$ & Glucose load & $1-2$ weeks & $5 d$ & $<4$ \\
\hline $\begin{array}{l}\text { Biorklund, 2005, } \\
\text { Netherlands, } \\
\text { Sweden }{ }^{(28)}\end{array}$ & 89 & $56 \cdot 0$ & $10 \cdot 0$ & $\mathrm{M} / \mathrm{F}$ & $25 \cdot 3$ & 3.2 & $\begin{array}{l}\text { Free-living hyper- } \\
\text { cholesterolaemic }\end{array}$ & Parallel & $\begin{array}{l}\text { Oat beverages } \\
\quad(10 \mathrm{~g} / \mathrm{d} \beta \text {-glucan })\end{array}$ & $\begin{array}{l}\text { Control beverage enriched } \\
\text { with rice starch }\end{array}$ & 3 weeks & 5 weeks & $\geq 4$ \\
\hline Maki, 2007, USA ${ }^{(29)}$ & 97 & 60.05 & 1.7 & $\mathrm{M} / \mathrm{F}$ & $32 \cdot 4$ & 0.9 & $\begin{array}{l}\text { Elevated blood } \\
\text { pressure }\end{array}$ & Parallel & $\begin{array}{l}\text { Oat bran, oatmeal and oat } \\
\text { power }(7.7 \mathrm{~g} / \mathrm{d} \beta \text {-glucan })\end{array}$ & Maltodextrin power & 4 weeks & 12 weeks & $\geq 4$ \\
\hline Queenan, 2007, USA ${ }^{(30)}$ & 75 & $45 \cdot 3$ & $2 \cdot 0$ & $\mathrm{M} / \mathrm{F}$ & \multicolumn{2}{|c|}{$\leq 30.0$} & $\begin{array}{l}\text { Hyper- } \\
\text { cholesterolaemic }\end{array}$ & Parallel & Oat powder (6g/d $\beta$-glucan) & $6 \mathrm{~g} / \mathrm{d}$ dextrose monohydrate & NR & 6 weeks & $\geq 4$ \\
\hline $\begin{array}{l}\text { Reyna-Villasmil, 2007, } \\
\text { Venezuela }^{(31)}\end{array}$ & 38 & 59.8 & 0.6 & M & $28 \cdot 3$ & 0.6 & Overweight & Parallel & $\begin{array}{l}\text { Oat soluble fibre bread } \\
(6 \mathrm{~g} / \mathrm{d} \beta \text {-glucan })\end{array}$ & $\begin{array}{l}\text { Whole-wheat bread with } \\
\text { negligible } \beta \text {-glucan }\end{array}$ & 1 week & 8 weeks & $<4$ \\
\hline $\begin{array}{l}\text { Panahi, 2007, } \\
\text { Canada }^{(17)}\end{array}$ & 11 & $34 \cdot 0$ & $5 \cdot 0$ & $\mathrm{M} / \mathrm{F}$ & $23 \cdot 0$ & 0.8 & Healthy & Cross-over & Oat drink (6g/d $\beta$-glucan) & $\begin{array}{l}\text { Combination of } 8 \mathrm{~g} \text { of } \\
\text { fructo-oligosaccharide } \\
\text { and } 3 \mathrm{~g} \text { of wheat bran }\end{array}$ & $3 d$ & $2 \mathrm{~h}$ & $\geq 4$ \\
\hline $\begin{array}{l}\text { Biorklund, 2008, } \\
\text { Sweden }^{(21)}\end{array}$ & 43 & 58.0 & $8 \cdot 2$ & $\mathrm{M} / \mathrm{F}$ & $25 \cdot 0$ & 3.1 & Healthy & Parallel & $\begin{array}{r}\text { Oat } \beta \text {-glucan soup } \\
(4 \mathrm{~g} / \mathrm{d} \beta \text {-glucan })\end{array}$ & Soup without $\beta$-glucan & 3 weeks & 5 weeks & $\geq 4$ \\
\hline $\begin{array}{l}\text { Granfeldt, 2008, } \\
\text { Sweden }^{(32)}\end{array}$ & 32 & 37.5 & $15 \cdot 2$ & $\mathrm{M} / \mathrm{F}$ & $22 \cdot 4$ & 0.6 & Healthy & Cross-over & Oat bran (3, $4 \mathrm{~g} / \mathrm{d} \beta$-glucan $)$ & $\begin{array}{l}\text { A serving packet without } \\
\beta \text {-glucan }\end{array}$ & 1 week & 1 week & $<4$ \\
\hline Liatis, 2009, Greece & 41 & 66.5 & 8.86 & $\mathrm{M} / \mathrm{F}$ & 27.01 & 3.7 & Type 2 diabetes & Parallel & $\begin{array}{l}\text { Oat } \beta \text {-glucan-enriched bread } \\
\quad(4 \mathrm{~g} / \mathrm{d} \beta \text {-glucan })\end{array}$ & Control bread & 3 weeks & 3 weeks & $\geq 4$ \\
\hline $\begin{array}{l}\text { Cugnet-Anceau, 2010, } \\
\text { Sweden, France }{ }^{(20)}\end{array}$ & 53 & 61.8 & 7.5 & $\mathrm{M} / \mathrm{F}$ & $20 \cdot 0$ & $35 \cdot 0$ & Type 2 diabetes & Parallel & $\begin{array}{l}\text { Soluble oat soups } \\
\text { (3.5 g/d } \beta \text {-glucan) }\end{array}$ & Soup without $\beta$-glucan & 3 weeks & 8 weeks & $\geq 4$ \\
\hline Beck, 2010, Finland ${ }^{(15)}$ & 56 & 37.4 & $5 \cdot 7$ & $\mathrm{~F}$ & $29 \cdot 2$ & $2 \cdot 2$ & Overweight & Parallel & Oat bran (5-6g/d $\beta$-glucan) & $\begin{array}{l}\text { High-fibre products without } \\
\beta \text {-glucan }\end{array}$ & $\mathrm{NR}$ & 12 weeks & $\geq 4$ \\
\hline $\begin{array}{l}\text { Juvonen, 2011, } \\
\text { Finland }^{(34)}\end{array}$ & 20 & $19 \cdot 0$ & 33.0 & $\mathrm{M} / \mathrm{F}$ & $19 \cdot 1$ & 24.8 & Healthy & Cross-over & $\begin{array}{l}\text { Oat bran pudding } \\
\text { (5.1 g/d } \beta \text {-glucan) }\end{array}$ & $\begin{array}{l}\text { A pudding with no added } \\
\text { cereal fibre }\end{array}$ & $\geq 2 d$ & $3 \mathrm{~h}$ & $<4$ \\
\hline McGeoch, 2013, UK ${ }^{(19)}$ & 27 & 60.9 & 1.23 & $\mathrm{M} / \mathrm{F}$ & 31.5 & 0.98 & Type 2 diabetes & Cross-over & $\begin{array}{l}\text { Oat-enriched diet } \\
\text { (3.9 g/d } \beta \text {-glucan) }\end{array}$ & $\begin{array}{l}\text { Habitual diet without } \\
\text { whole-grain or oat-based } \\
\text { products }\end{array}$ & 0 week & 16 weeks & $<4$ \\
\hline
\end{tabular}

$M$, male; F, female; NR, not reported. 
Table 3. Pooled effects of oat intake on glucose control and insulin sensitivity

(Number of studies, number of subjects, net changes and $95 \%$ confidence intervals)

\begin{tabular}{|c|c|c|c|c|c|c|c|c|}
\hline \multirow[b]{2}{*}{ Variables } & \multirow[b]{2}{*}{$\begin{array}{l}\text { No. of } \\
\text { studies }\end{array}$} & \multicolumn{2}{|c|}{ No. of subjects } & \multirow[b]{2}{*}{$\begin{array}{c}\text { Net } \\
\text { change }\end{array}$} & \multirow[b]{2}{*}{$95 \% \mathrm{Cl}$} & \multicolumn{2}{|c|}{ Test of heterogeneity ${ }^{\star}$} & \multirow[b]{2}{*}{$P+$} \\
\hline & & $\begin{array}{c}\text { Treatment } \\
\text { groups }\end{array}$ & $\begin{array}{l}\text { Control } \\
\text { groups }\end{array}$ & & & $P$ & $I^{2}(\%)$ & \\
\hline Fasting glucose $(\mathrm{mmol} / \mathrm{l})$ & 13 & 289 & 269 & -0.04 & $-0.17,0.09$ & 0.0002 & 68 & 0.59 \\
\hline Fasting insulin (pmol/l) & 10 & 217 & 205 & $-6 \cdot 29$ & $-12 \cdot 32,-0 \cdot 27$ & 0.57 & 0 & 0.04 \\
\hline GAUC $¥(\min \mathrm{mmol} / \mathrm{l})$ & 6 & 112 & 103 & $-30 \cdot 23$ & $-43 \cdot 65,-16 \cdot 81$ & 0.22 & 27 & $<0.0001$ \\
\hline $\mathrm{HbA1c}(\%)$ & 3 & 79 & 69 & -0.02 & $-0.23,0.18$ & 0.07 & 62 & 0.83 \\
\hline HOMA-IR (units) & 3 & 72 & 66 & -0.64 & $-1.83,0.55$ & 0.02 & 75 & 0.29 \\
\hline
\end{tabular}

GAUC, Glucose AUC; HbA1c, glycated Hb; HOMA-IR, homeostatic model assessment-insulin resistance.

${ }^{\star} P$ and $I^{2}$ were used for heterogeneity assessment by Cochran's $Q$ test, and $P<0 \cdot 1$ or $I^{2}>50 \%$ was considered to indicate significant heterogeneity across the studies.

$\dagger P$ for meta-analysis: $P<0.05$ was considered statistically significant.

$\ddagger 0-120 \mathrm{~min}$.

between oat intake and fasting glucose concentrations was indicated by the meta-regression analyses $(P=0 \cdot 91)$.

\section{Effect of oat intake on fasting insulin concentrations}

Data on the effect of oat intake on fasting insulin concentrations were reported by ten studies in nine articles, and a significant reduction in fasting insulin concentrations was observed in subjects who consumed oats $(-6.29$ (95\% CI $-12.32,-0.27) \mathrm{pmol} / \mathrm{l} ; P=0.04$; Table 3 and Fig. 4) than in the control subjects. No significant heterogeneity was observed among the studies $\left(I^{2}=0\right)$. No publication bias was indicated by the funnel plot (Fig. 5) and Egger's test
$(P=0 \cdot 39)$. No dose-effect relationship between oat intake and fasting insulin concentrations $(P=0.58)$ was indicated by the meta-regression analyses.

\section{Effect of oat intake on glucose AUC values, glycated $\mathrm{Hb}$ concentrations and homeostatic model assessment-insulin resistance values}

Data on the effect of oat intake on GAUC values, HbA1c concentrations and HOMA-IR values were reported in five, three and three articles, respectively. As shown in Table 3, oat intake significantly decreased GAUC values $(-30 \cdot 23$ (95\% CI $-43.65,-16.81) \mathrm{min} \times \mathrm{mmol} / \mathrm{l} ; P<0.0001)$, but did

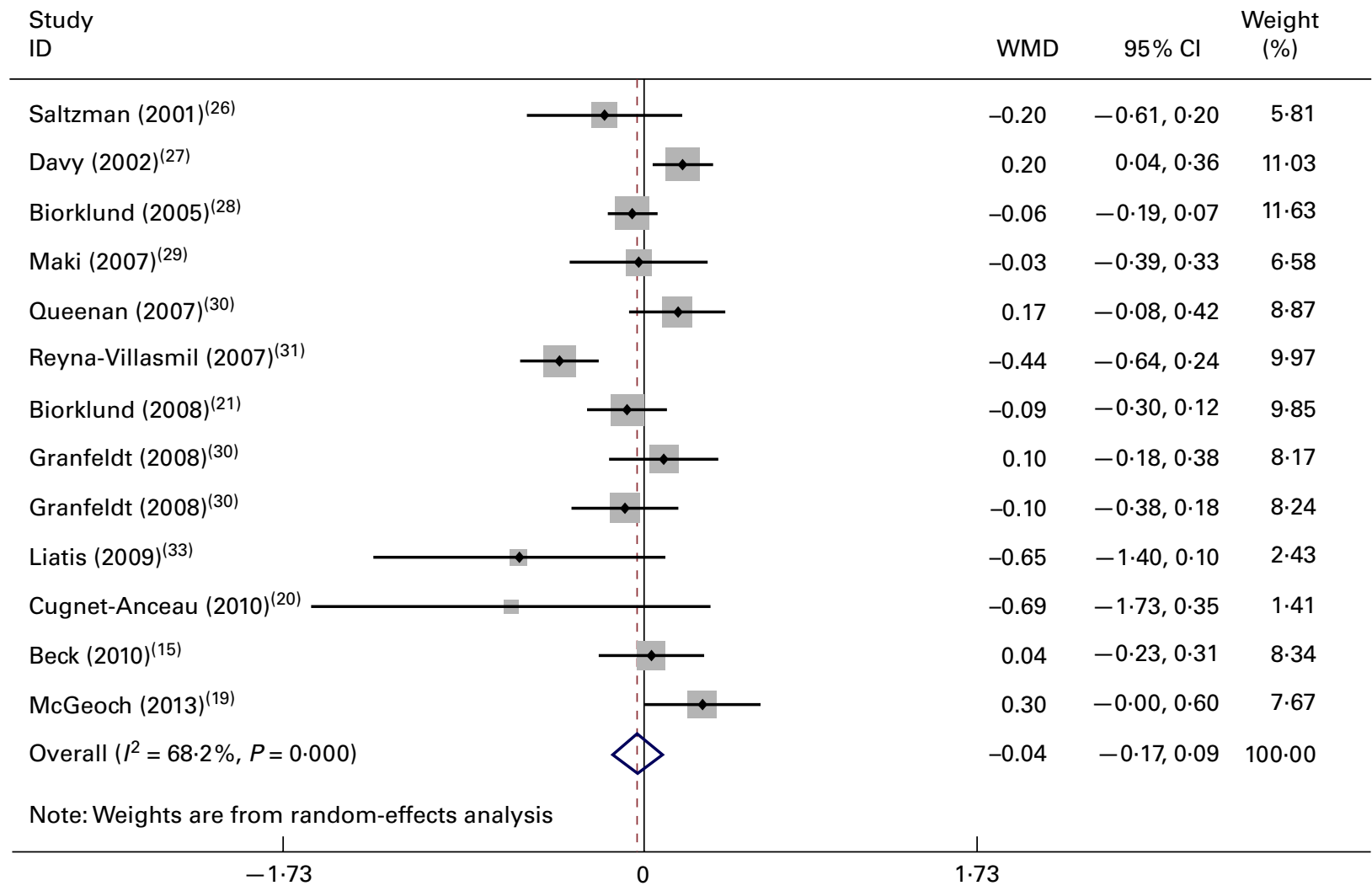

Fig. 2. Results of the meta-analysis carried out to investigate the effect of oat intake on fasting glucose concentrations. The results were obtained using a random-effects model. There were two series in the study carried out by Granfeldt et al. ${ }^{(32)}$. WMD, weighted mean difference. (A colour version of this figure can be found online at http://www.journals.cambridge.org/bjn). 


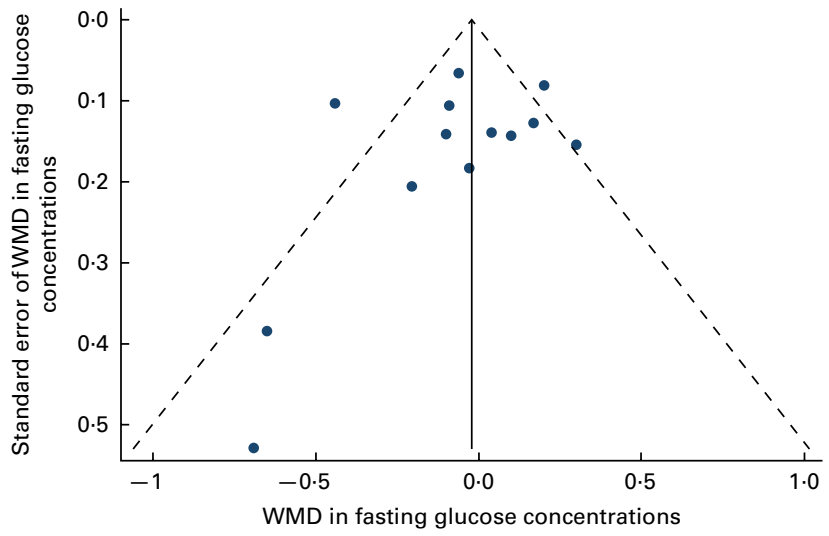

Fig. 3. Funnel plot with pseudo- $95 \% \mathrm{Cl}$ for the effect of oat intake on fasting glucose concentrations. WMD, weighted mean difference. (A colour version of this figure can be found online at http://www.journals.cambridge.org/bjn).

not significantly affect HbA1c concentrations or HOMA-IR values $(P=0.83$ and 0.29 , respectively). Low heterogeneity was observed among the studies with regard to the effect of oat intake on GAUC values $\left(I^{2}=27 \%\right)$, whereas high heterogeneity was observed with regard to the effect of oat intake on HbA1c concentrations and HOMA-IR values $\left(I^{2}=62\right.$ and $75 \%$, respectively). Funnel plots and Egger's test did not indicate any significant publication bias with regard to GAUC values, HbA1c concentrations and HOMA-IR values (Egger's test: $P=0.65,0.15$ and 0.15 , respectively). No dose-effect relationship was found between oat intake and GAUC values $(P=0.06)$. A dose-effect analysis was not carried out for HbA1c concentrations or HOMA-IR values, as data on these two variables were reported by only a limited number of studies.

\section{Sensitivity and subgroup analyses}

As shown in Table 4, there was no substantial change in the effect of oat intake on fasting glucose and insulin concentrations by subgroup analyses. The results did not change on the exclusion of any individual study during the sensitivity analyses. The subgroup analyses of fasting glucose concentrations indicated that the overall outcome of fasting glucose responses was not affected by subgroups including regions, healthy status, study design, $\beta$-glucan content in oats, intervention period or Jadad score and no significant difference was found. Significant reductions in fasting insulin concentrations were observed after oat intake in the subgroups of both European countries and the USA. Significant reductions in fasting insulin concentrations were also observed in the subgroups of subjects who were healthy or had metabolic disease risk. Among the study design subgroups, subgroup analyses indicated that oat intake had a lowering effect on fasting insulin concentrations in subgroups with a parallel design, but that it did not affect fasting insulin concentrations in subgroups with a cross-over design. Significant reductions in fasting insulin concentrations were observed in subgroups that consumed oats at both high doses $(\geq 5 \mathrm{~g} / \mathrm{d})$ and low doses $(<5 \mathrm{~g} / \mathrm{d})$. In addition, when stratifying studies

\begin{tabular}{|c|c|c|c|}
\hline $\begin{array}{l}\text { Study } \\
\text { ID }\end{array}$ & WMD & $95 \% \mathrm{Cl}$ & $\begin{array}{c}\text { Weight } \\
(\%)\end{array}$ \\
\hline Saltzman $(2001)^{(26)}$ & $-19 \cdot 40$ & $-42 \cdot 24,3 \cdot 44$ & $6 \cdot 96$ \\
\hline $\operatorname{Davy}(2002)^{(27)}$ & 8.90 & $-32 \cdot 57,14 \cdot 77$ & $6 \cdot 48$ \\
\hline Biorklund $(2005)^{(28)}$ & -7.87 & $-18.78,3.04$ & $30 \cdot 51$ \\
\hline Maki $(2007)^{(29)}$ & 1.40 & $-24 \cdot 91,27 \cdot 71$ & $5 \cdot 25$ \\
\hline Queenan $(2007)^{(30)}$ & $2 \cdot 70$ & $-19 \cdot 83,25 \cdot 23$ & $7 \cdot 16$ \\
\hline Granfeldt $(2008)^{(32)}$ & 0.00 & $-23 \cdot 58,23 \cdot 58$ & 6.53 \\
\hline Granfeldt $(2008)^{(32)}$ & $-7 \cdot 00$ & $-34 \cdot 23,20 \cdot 23$ & 4.90 \\
\hline Liatis $(2009)^{(33)}$ & $-48 \cdot 76$ & $-87.70,-9.82$ & $2 \cdot 40$ \\
\hline Beck $(2010)^{(15)}$ & $-1 \cdot 67$ & $-20 \cdot 77,17 \cdot 43$ & 9.96 \\
\hline McGeoch $(2013)^{(19)}$ & $-2 \cdot 79$ & $-16 \cdot 32,10 \cdot 74$ & 19.85 \\
\hline Overall $\left(I^{2}=0.0 \%, P=0.569\right)$ & $-6 \cdot 29$ & $-12 \cdot 32,-0 \cdot 27$ & $100 \cdot 00$ \\
\hline$\perp$ & $\perp$ & & \\
\hline
\end{tabular}

Fig. 4. Results of the meta-analysis carried out to investigate the effect of oat intake on fasting insulin concentrations. The results were obtained using a fixedeffects model. There were two series in the study carried out by Granfeldt et al. ${ }^{(32)}$. WMD, weighted mean difference. (A colour version of this figure can be found online at http://www.journals.cambridge.org/bjn). 


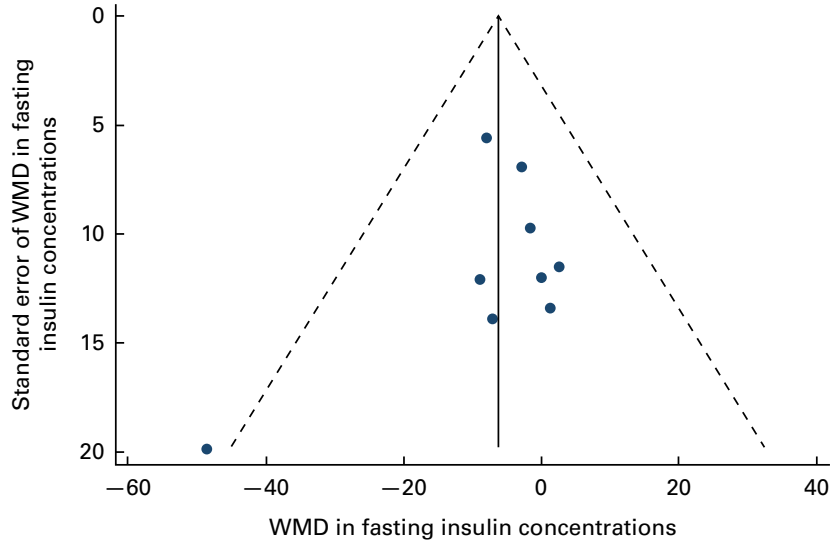

Fig. 5. Funnel plot with pseudo- $95 \% \mathrm{Cl}$ for the effect of oat intake on fasting insulin concentrations. WMD, weighted mean difference. (A colour version of this figure can be found online at http://www.journals.cambridge.org/bjn).

according to the intervention period, significant reductions in fasting insulin concentrations were observed in the subgroups of long-term studies ( $\geq 8$ weeks), but not in those of short-term studies ( $<8$ weeks). Finally, a significant reduction in fasting insulin concentrations was observed only in those studies with high Jadad scores.

\section{Discussion}

In the present meta-analysis, we found that oat intake significantly lowered fasting insulin concentrations and GAUC values, but had no significant effect on fasting glucose concentrations, HbA1c concentrations and HOMA-IR values. Our assessment of the effect of oat intake on GAUC values, HbA1c concentrations and HOMA-IR values was limited due to the small number of studies available for analysis.
Consistent with what we found, a study has shown that oat intake significantly decreases insulin responses and postprandial plasma glucose responses in rats ${ }^{(35)}$. The effects are partly due to the ability of oat $\beta$-glucan to increase the viscosity of intestinal content and slow the digestion of carbohydrates and also delay the gastric emptying rate concomitantly, causing satiety for extended periods of time ${ }^{(36)}$. Moreover, $\beta$-glucan could be completely fermented by microflora in the large intestine, leading to the release of SCFA and then lowering of postprandial plasma glucose concentrations ${ }^{(10,37,38)}$. Lv et al. ${ }^{(39)}$ demonstrated that dihydroavenanthramide $\mathrm{D}$, which is the active component of oats, protects pancreatic $\beta$-cells from cytokine and streptozotocin toxicity and prevents the development of type 1 diabetes in streptozotocin-treated mice. In addition, oats have been demonstrated to possess antioxidant activity ${ }^{(40)}$ and enhance insulin signalling by changing the expression of glucose and lipid metabolism genes, which in turn improves insulin sensitivity ${ }^{(41)}$. Stratification according to the study design indicated that oat intake had a lowering effect on fasting insulin concentrations in subgroups with a parallel design, but had no effect in subgroups with a cross-over design. This difference could be due to the small number of participants in RCT with a cross-over design, four of which were also of the shortest duration among the included trials. Significant reductions in fasting insulin concentrations were observed in subgroups that consumed oats at both high doses $(\geq 5 \mathrm{~g} / \mathrm{d})$ and low doses $(<5 \mathrm{~g} / \mathrm{d})$, but notably oat intake at low doses was found to result in a slightly greater decrease in fasting insulin concentrations. The reason for this is unknown, as no study had reported an appropriate dose or dose-response relationship between oat intake and fasting insulin concentrations. We speculated that this might be due to an increase in carbohydrate content during high-dose oat intake or to the lowering

Table 4. Results of the subgroup analyses of the effect of oat intake on fasting glucose and insulin concentrations (Number of studies, net changes and $95 \%$ confidence intervals)

\begin{tabular}{|c|c|c|c|c|c|c|c|c|}
\hline \multirow[b]{2}{*}{ Subgroups } & \multicolumn{4}{|c|}{ Fasting glucose } & \multicolumn{4}{|c|}{ Fasting insulin } \\
\hline & $\begin{array}{l}\text { No. of } \\
\text { studies }\end{array}$ & $\begin{array}{l}\text { Net change } \\
(\mathrm{mmol} / \mathrm{l})\end{array}$ & $95 \% \mathrm{Cl}$ & $I^{2}(\%)$ & $\begin{array}{l}\text { No. of } \\
\text { studies }\end{array}$ & $\begin{array}{l}\text { Net change } \\
(\mathrm{pmol} / \mathrm{l})\end{array}$ & $95 \% \mathrm{Cl}$ & $I^{2}(\%)$ \\
\hline Overall & 13 & -0.04 & $-0.17,0.09$ & 68 & 10 & $-6 \cdot 29$ & $-12.32,-0.27$ & 0 \\
\hline \multicolumn{9}{|l|}{ Regions } \\
\hline European countries & 8 & -0.03 & $-0.11,0.06$ & 34 & 6 & $-6 \cdot 25$ & $-13.25,-0.75$ & 8 \\
\hline USA & 5 & -0.05 & $-0.34,0.23$ & 85 & 4 & -8.43 & $-18.28,-0.43$ & 0 \\
\hline \multicolumn{9}{|l|}{ Health status } \\
\hline Metabolic disease risk & 9 & -0.03 & $-0.21,0.15$ & 77 & 7 & $-6 \cdot 64$ & $-12.31,-0.03$ & 1 \\
\hline Healthy & 4 & -0.06 & $-0.20,0.07$ & 0 & 3 & -9.21 & $-23.26,-0.84$ & 0 \\
\hline \multicolumn{9}{|l|}{ Study design } \\
\hline Parallel & 10 & -0.08 & $-0.24,0.08$ & 72 & 7 & -7.85 & $-15.13,-0.58$ & 14 \\
\hline Cross-over & 3 & 0.09 & $-0.08,0.25$ & 45 & 3 & -2.87 & $-13.64,7.91$ & 0 \\
\hline \multicolumn{9}{|l|}{$\beta$-Glucan content in oats } \\
\hline$<5 \mathrm{~g} / \mathrm{d}$ (median) & 7 & -0.03 & $-0.15,0.09$ & 45 & 5 & -9.41 & $-18.86,-1.05$ & 35 \\
\hline$\geq 5 \mathrm{~g} / \mathrm{d}$ (median) & 6 & -0.02 & $-0.22,0.17$ & 81 & 5 & $-6 \cdot 85$ & $-14.67,-0.97$ & 0 \\
\hline \multicolumn{9}{|l|}{ Intervention period } \\
\hline$<8$ weeks (median) & 6 & -0.03 & $-0.12,0.06$ & 25 & 5 & $-7 \cdot 22$ & $-15 \cdot 62,1 \cdot 18$ & 27 \\
\hline$\geq 8$ weeks (median) & 7 & -0.05 & $-0.30,0.20$ & 81 & 5 & $-10 \cdot 31$ & $-17.96,-0.35$ & 0 \\
\hline \multicolumn{9}{|l|}{ Jadad score } \\
\hline Low $(<4)$ & 6 & -0.02 & $-0.27,0.23$ & 83 & 5 & $-6 \cdot 32$ & $-15 \cdot 33,2 \cdot 70$ & 0 \\
\hline High $(\geq 4)$ & 7 & -0.04 & $-0.13,0.05$ & 19 & 5 & $-8 \cdot 28$ & $-14.38,-1.83$ & 31 \\
\hline
\end{tabular}


of fasting insulin concentrations by the active component of oats. However, the results of the meta-regression analyses carried out indicated no significant dose-response relationship between oat intake and fasting insulin concentrations $(P=0.58)$. So, it is difficult to confirm the optimal dose for a dietary guideline to improve diabetic health and more in-depth studies on mechanisms through which oats lower fasting insulin concentrations are required. When studies were stratified according to the intervention period, significant reductions in fasting insulin concentrations were observed in the subgroups of long-term studies ( $\geq 8$ weeks), but not in those of short-term studies ( $<8$ weeks). We speculated that it might take a long period for oats to exert their biological effects. Finally, a significant reduction in fasting insulin concentrations was observed only in studies with high Jadad scores.

There has been conflicting evidence for the effect of oat intake on fasting glucose concentrations. A recent study has demonstrated oat products to significantly decrease fasting blood glucose and glycosylated serum protein concentrations in streptozotocin-induced diabetic mice ${ }^{(42)}$. Several studies in human subjects have also reported the same results ${ }^{(10-15)}$. However, some studies have found oat-enriched products to have no effects on fasting blood glucose concentrations ${ }^{(18-21)}$. In the present meta-analysis, we found that there was a slight decrease in fasting glucose concentrations in subjects who consumed oat-enriched products, but the difference was not significant. This conclusion was consistent with that of a recently published meta-analysis that included 1250 participants from cohort studies, dose-response studies, and pre- and post-treatment studies and reported study designs (randomised, cross-over, parallel, etc.) with or without health conditions ${ }^{(43)}$. However, the subgroup analyses carried out in the present meta-analysis indicated oat intake to slightly lower fasting glucose concentrations in long-term and high-quality RCT conducted in human subjects with a parallel design, which might be interesting candidates for future research.

The present meta-analysis has several limitations. The sample sizes of RCT investigating the effect of oat intake on glycaemic control and insulin sensitivity are relatively small and available studies reporting data on the effect of oat intake on HbA1c and HOMA-IR values are rather limited, which could have affected the results of the analysis. In addition, assessment of results for glucose control or insulin sensitivity was not the primary goal of most of the studies included in the present meta-analysis. Potential language bias could have occurred as articles that were not published in English were excluded.

Oats can be classified as hulled and naked oats. Naked oats, which are mainly produced in China, have a non-lignified husk, which becomes detached readily during harvesting. Naked oats have been shown to contain higher proportions of protein and oil and a lower content of lignin compared with hulled oats and there is a substantial variation in the contents of phytochemicals ${ }^{(44)}$. No significant differences in $\beta$-glucan content between naked and hulled oats have been reported $^{(44,45)}$. Naked oats have also been demonstrated to lead to metabolic control and CVD risk prevention in T2DM patients with the metabolic syndrome ${ }^{(46)}$. However, the existing studies have focused on only hulled oats so far. Studies on naked oats are still limited and more studies are required to assess any beneficial effects.

In conclusion, the results of the meta-analysis indicated oat intake to significantly lower fasting insulin concentrations and GAUC values, but not to have any significant effect on fasting glucose concentrations, HbA1c concentrations and HOMA-IR values. The subgroup analyses indicated that additional long-term and high-quality RCT conducted in human subjects with a parallel design are required to further investigate the effect of oat intake on fasting glucose concentrations, which may provide evidence for the therapeutic potential of oats in diabetic patients or for preventing glucose dysregulation in those at a risk of DM.

The present work was supported by research grants from the National Natural Science Foundation of China (no. 81372995) and the Beijing Key Laboratory of Toxicological Research and Risk Assessment for Food Safety. The authors cordially thank Yuan Zhang, the Department of Clinical Epidemiology and Biostatistics, McMaster University, for helping analyse data.

\section{Acknowledgements}

The authors' contributions are as follows: L. B. and Y. L. conceived the research; L. B. and X. C. searched the databases and screened all the articles obtained according to the inclusion criteria and exclusion criteria; L. B. and M. X. conducted the critical appraisal; X. C. and M. X. extracted detailed information; L. B. analysed the data and wrote the draft of the article; X. C. contributed to the writing and reviewing of the article; L. B. was responsible for the critical revision of the manuscript.

None of the authors has any conflicts of interest to declare.

\section{References}

1. Danaei G, Finucane MM, Lu Y, et al. (2011) National, regional, and global trends in fasting plasma glucose and diabetes prevalence since 1980: systematic analysis of health examination surveys and epidemiological studies with 370 country-years and 2.7 million participants. Lancet 378, 31-40.

2. Shaw JE, Sicree RA \& Zimmet PZ (2010) Global estimates of the prevalence of diabetes for 2010 and 2030. Diabetes Res Clin Pract 87, 4-14.

3. Rathmann W \& Giani G (2004) Global prevalence of diabetes: estimates for the year 2000 and projections for 2030 . Diabetes Care 27, 2568-2569.

4. The Diabetes Control and Complications Trial Research Group (1995) The effect of intensive diabetes therapy on the development and progression of neuropathy. Ann Intern Med 122, 561-568.

5. Nathan DM, Cleary PA, Backlund JY, et al. (2005) Intensive diabetes treatment and cardiovascular disease in patients with type 1 diabetes. $N$ Engl J Med 353, 2643-2653.

6. Li G, Zhang P, Wang J, et al. (2008) The long-term effect of lifestyle interventions to prevent diabetes in the China Da 
Qing Diabetes Prevention Study: a 20-year follow-up study. Lancet 371, 1783-1789.

7. Ramachandran A, Snehalatha C, Mary S, et al. (2006) The Indian Diabetes Prevention Programme shows that lifestyle modification and metformin prevent type 2 diabetes in Asian Indian subjects with impaired glucose tolerance (IDPP-1). Diabetologia 49, 289-297.

8. Sadiq Butt M, Tahir-Nadeem M, Khan MK, et al. (2008) Oat: unique among the cereals. Eur J Nutr 47, 68-79.

9. Haboubi NY, Taylor S \& Jones S (2006) Coeliac disease and oats: a systematic review. Postgrad Med J 82, 672-678.

10. Battilana P, Ornstein K, Minehira K, et al. (2001) Mechanisms of action of beta-glucan in postprandial glucose metabolism in healthy men. Eur J Clin Nutr 55, 327-333.

11. Tappy L, Gügolz E \& Würsch P (1996) Effects of breakfast cereals containing various amounts of beta-glucan fibers on plasma glucose and insulin responses in NIDDM subjects. Diabetes Care 19, 831-834.

12. Tapola N, Karvonen H, Niskanen L, et al. (2005) Glycemic responses of oat bran products in type 2 diabetic patients. Nutr Metab Cardiovasc Dis 15, 255-261.

13. Pick ME, Hawrysh ZJ, Gee MI, et al. (1996) Oat bran concentrate bread products improve long-term control of diabetes: a pilot study. J Am Diet Assoc 96, 1254-1261.

14. Nazare JA, Normand S, Oste Triantafyllou A, et al. (2009) Modulation of the postprandial phase by beta-glucan in overweight subjects: effects on glucose and insulin kinetics. Mol Nutr Food Res 53, 361-369.

15. Beck EJ, Tapsell LC, Batterham MJ, et al. (2010) Oat betaglucan supplementation does not enhance the effectiveness of an energy-restricted diet in overweight women. Br J Nutr 103, 1212-1222.

16. Braaten JT, Wood PJ, Scott FW, et al. (1991) Oat gum, a soluble fiber which lowers glucose and insulin in normal individuals after an oral glucose load: comparison with guar gum. Am J Clin Nutr 53, 1425-1430.

17. Panahi S, Ezatagha A, Temelli F, et al. (2007) $\beta$-Glucan from two sources of oat concentrates affect postprandial glycemia in relation to the level of viscosity. J Am Coll Nutr 26, 639-644.

18. Liljeberg HG, Granfeldt YE \& Björck IM (1996) Products based on a high fiber barley genotype, but not on common barley or oats, lower postprandial glucose and insulin responses in healthy humans. J Nutr 126, 458-466.

19. McGeoch SC, Johnstone AM, Lobley GE, et al. (2013) A randomized crossover study to assess the effect of an oat-rich diet on glycaemic control, plasma lipids and postprandial glycaemia, inflammation and oxidative stress in Type 2 diabetes. Diabet Med 30, 1314-1323.

20. Cugnet-Anceau C, Nazare JA, Biorklund M, et al. (2010) A controlled study of consumption of beta-glucan-enriched soups for 2 months by type 2 diabetic free-living subjects. Br J Nutr 103, 422-428.

21. Biorklund M, Holm J \& Onning G (2008) Serum lipids and postprandial glucose and insulin levels in hyperlipidemic subjects after consumption of an oat beta-glucan-containing ready meal. Ann Nutr Metab 52, 83-90.

22. Oremus M, Wolfson C, Perrault A, et al. (2001) Interrater reliability of the modified Jadad quality scale for systematic reviews of Alzheimer's disease drug trials. Dement Geriatr Cogn Disord 12, 232-236.

23. Whitehead A (2002) Meta-analysis of Controlled Clinical Trials. pp. 60-1204. Chichester: John Wiley \& Sons.

24. Higgins JP, Thompson SG, Deeks JJ, et al. (2003) Measuring inconsistency in meta-analyses. BMJ 327, 557-560.
25. Egger M, Davey SG, Schneider M, et al. (1997) Bias in meta-analysis detected by a simple, graphical test. BMJ 315, 629-634.

26. Saltzman E, Das SK, Lichtenstein AH, et al. (2001) An oatcontaining hypocaloric diet reduces systolic blood pressure and improves lipid profile beyond effects of weight loss in men and women. $J$ Nutr 131, 1465-1470.

27. Davy BM, Davy KP, Ho RC, et al. (2002) High-fiber oat cereal compared with wheat cereal consumption favorably alters LDL-cholesterol subclass and particle numbers in middleaged and older men. Am J Clin Nutr 76, 351-358.

28. Biorklund M, van Rees A, Mensink RP, et al. (2005) Changes in serum lipids and postprandial glucose and insulin concentrations after consumption of beverages with beta-glucans from oats or barley: a randomised dose-controlled trial. Eur J Clin Nutr 59, 1272-1281.

29. Maki KC, Galant R, Samuel P, et al. (2007) Effects of consuming foods containing oat beta-glucan on blood pressure, carbohydrate metabolism and biomarkers of oxidative stress in men and women with elevated blood pressure. Eur J Clin Nutr 61, 786-795.

30. Queenan KM, Stewart ML, Smith KN, et al. (2007) Concentrated oat beta-glucan, a fermentable fiber, lowers serum cholesterol in hypercholesterolemic adults in a randomized controlled trial. Nutr J 6, 6 .

31. Reyna-Villasmil N, Bermudez-Pirela V, Mengual-Moreno E, et al. (2007) Oat-derived beta-glucan significantly improves HDLC and diminishes LDLC and non-HDL cholesterol in overweight individuals with mild hypercholesterolemia. Am J Ther 14, 203-212.

32. Granfeldt Y, Nyberg L \& Bjorck I (2008) Muesli with $4 \mathrm{~g}$ oat beta-glucans lowers glucose and insulin responses after a bread meal in healthy subjects. Eur J Clin Nutr 62, 600-607.

33. Liatis S, Tsapogas P, Chala E, et al. (2009) The consumption of bread enriched with betaglucan reduces LDL-cholesterol and improves insulin resistance in patients with type 2 diabetes. Diabetes Metab 35, 115-120.

34. Juvonen KR, Salmenkallio-Marttila M, Lyly M, et al. (2011) Semisolid meal enriched in oat bran decreases plasma glucose and insulin levels, but does not change gastrointestinal peptide responses or short-term appetite in healthy subjects. Nutr Metab Cardiovasc Dis 21, 748-756.

35. Zhang PP, Hu XZ, Zhen HM, et al. (2012) Oat $\beta$-glucan increased ATPases activity and energy charge in small intestine of rats. J Agric Food Chem 60, 9822-9827.

36. Hlebowicz J (2009) Postprandial blood glucose response in relation to gastric emptying and satiety in healthy subjects. Appetite 53, 249-252.

37. Behall KM, Scholfield DJ, Hallfrisch JG, et al. (2006) Consumption of both resistant starch and beta-glucan improves postprandial plasma glucose and insulin in women. Diabetes Care 29, 975-981.

38. Drzikova B, Dongowski G \& Gebhardt E (2005) Dietary fibre-rich oat-based products affect serum lipids, microbiota, formation of short-chain fatty acids and steriods in rats. $\mathrm{Br}$ J Nutr 94, 1012-1025.

39. Lv N, Song MY, Lee YR, et al. (2009) Dihydroavenanthramide D protects pancreatic beta-cells from cytokine and streptozotocin toxicity. Biochem Biophys Res Commun 387, $97-102$.

40. Ren Y, Yang X, Niu X, et al. (2011) Chemical characterization of the avenanthramide-rich extract from oat and its effect on D-galactose-induced oxidative stress in mice. J Agric Food Chem 59, 206-211. 
41. Choi JS, Kim H, Jung MH, et al. (2010) Consumption of barley beta-glucan ameliorates fatty liver and insulin resistance in mice fed a high-fat diet. Mol Nutr Food Res 54, 1004-1013.

42. Shen RL, Cai FL, Dong JL, et al. (2011) Hypoglycemic effects and biochemical mechanisms of oat products on streptozotocin-induced diabetic mice. J Agric Food Chem 59, $8895-8900$.

43. Tiwari U \& Cummins E (2011) Meta-analysis of the effect of $\beta$-glucan intake on blood cholesterol and glucose levels. Nutrition 27, 1008-1016.

44. Shewry PR, Piironen V, Lampi AM, et al. (2008) Phytochemical and fiber components in oat varieties in the
HEALTHGRAIN Diversity Screen. I Agric Food Chem 56, 9777-9784.

45. Andersson AA, Lampi AM, Nyström L, et al. (2008) Phytochemical and fiber components in barley varieties in the HEALTHGRAIN Diversity Screen. J Agric Food Chem 56, 9767-9776.

46. Ma X, Gu J, Zhang Z, et al. (2013) Effects of Avena nuda L. on metabolic control and cardiovascular disease risk among Chinese patients with diabetes and meeting metabolic syndrome criteria: secondary analysis of a randomized clinical trial. Eur J Clin Nutr 67, $1291-1297$. 